Secuencia (2004), 58, enero-abril, 161-188

ISSN: 0186-0348, ISSN electrónico: 2395-8464 DOI: http://dx.doi.org/10.18234/secuencia.v0i58.843

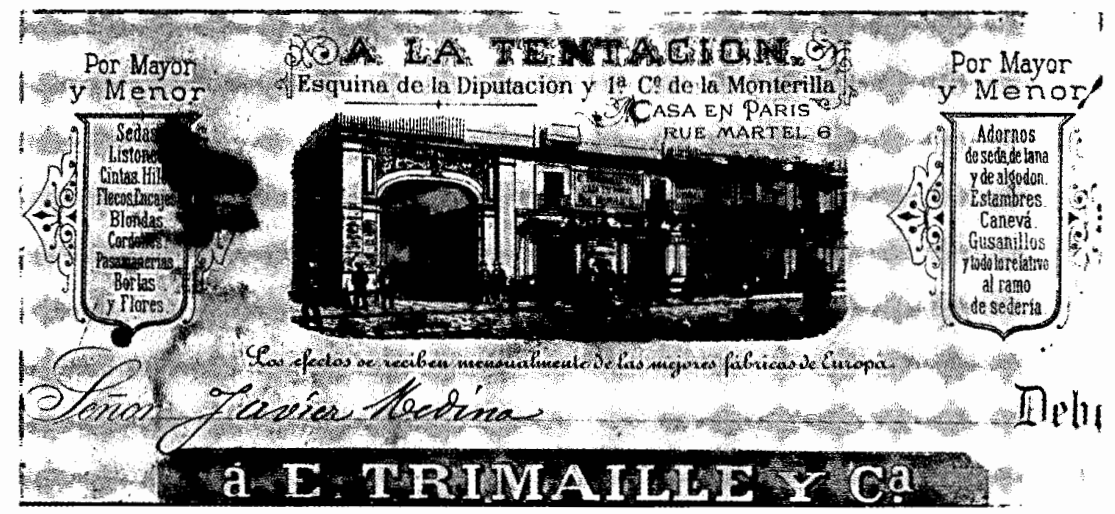




\section{Mirian Galante}

Becaria predoctoral en el Departamento de Historia de América del Instituto de Historia del Consejo Superior de Investigaciones Científicas (CSIC), en Madrid. Licenciada en Historia Moderna y Contemporánea por la Universidad Autónoma de Madrid. Actualmente realiza la tesis de doctorado sobre el pensamiento político mexicano de la primera mitad del siglo xIx.

\section{Resumen}

En el presente ensayo se presenta una reordenación sistemática de las producciones más recientes que han tratado desde la perspectiva histórica el proceso de consolidación del Estado liberal mexicano. El texto recoge y analiza dichas propuestas con el fin de presentar una panorámica crítica sobre los trabajos que tratan acerca de una temárica vinculada a uno de los debates historiográficos más relevantes y enriquecedores en el ámbito latinoamericanista en general y mexicanista en concreto, y que a la vez está generando nuevos planteamientos que subvierten los tópicos tradicionalmente consolidados por la historia oficial.

Palabras clave:

Historiografía, México, liberalismo, pensamiento político, siglo XIX.

\section{Abstract}

This essay provides a systematic rearrangement of the most recent publications that deal with the consolidation of the Mexican liberal state. from a historical perspective. The text compiles and analyzes these proposals to present a critical overview of the studies on an issue that has sparked one of the most important and enriching historiographic debates in the Latin American sphere in general and the Mexican sphere in particular, and which has also suggested new approaches that question the clichés traditionally consolidated by official history.

\section{Key words:}

Historiography, Mexico, liberalism, political thought, 19th century.

Fecha de recepción:

abril de 2003

Fecha de aceptación: julio de 2003 


\title{
El liberalismo en la historiografía mexicanista de los últimos veinte años*
}

\author{
Mirian Galante
}

L a crisis de legitimidad sin precedentes experimentada por el partido gobernante a mediados de los años ochenta de la centuria pasada supuso el inicio de una nueva situación política en México. La fractura iniciada la década anterior entre la política y la historia, matrimonio feliz desde el triunfo de la revolución mexicana, se agudizó al tiempo que se concretó en dos direcciones. ${ }^{1}$ Por un lado, la necesidad de abrir nuevos espacios de interpretación en contraste con una historia oficial que había servido durante 80 años muy oportunamente para justificar la política del partido-gobierno, y por otro, la de comprender mejor el momento de gestación del Estado moderno mexicano, de tal manera que al conocer la naturaleza de su proceso de definición iniciado tras el éxito de la lucha independentista se esperaba poder encontrar nuevas

* El presente trabajo se ha podido realizar gracias al apoyo de una beca de Formación de Personal Investigador otorgada por la Comunidad de Madrid a la autora para la realización de su tesis doctoral. Agradezco las sugerencias de Mónica Quijada, Marta Irurozqui, Juan Carlos Velasco, Carmen Nava y Rosalina Ríos a una versión anterior de este texto.

${ }^{1}$ Este distanciamiento entre ambas se había iniciado en los años setenta, con la crítica de Cosío Villegas al mito liberal de la historiografía tradicional mexicana. vías de reconstitución nacional a partir de las cuales intentar subsanar dicha crisis sin generar una ruptura del marco político del momento. A la vez, el redescubrimiento por parte de la historiografía de las prácticas políticas de la sociedad civil enriqueció la averiguación histórica, puesto que planteó nuevas interrogantes que igualmente fomentaron el interés por ese periodo. ${ }^{2}$ El resultado de todo ello se aprecia en la enorme proliferación de estudios acerca del siglo XIX mexicano ocurrida en los últimos años. ${ }^{3}$ Prácticamente la totalidad de estos análisis vincula el proyecto de construcción nacional con la introducción de los principios liberales y su definición como los principios rectores sobre los que fundar el nuevo Estado mexicano. Es más, de alguna manera identifican la sustitución del antiguo orden no-

${ }^{2}$ La publicación del libro de Guerra, México, 1988, abrió una perspectiva de análisis que contribuyó de manera significativa al aumento del interés por el siglo XIX.

${ }^{3} \mathrm{El}$ interés por este periodo ha dado lugar no sólo a una cantidad ingente de libros, sino también a la creación de una revista dedicada exclusivamente al análisis del siglo XIX mexicano. Siglo XIX. Revista de Historia fue fundada en 1986 bajo el auspicio de la Facultad de Filosofía y Letras de la Universidad Autónoma de Nuevo León. Para ver el desarrollo de esta publicación, Cerutti, "Siglo", 2001, pp. 899-920. 
vohispano con el liberal mediante la modernización política del país. ${ }^{4}$

En el presente texto se presentará una revisión crítica de la prolífica literatura existente acerca de la naturaleza del liberalismo mexicano en el siglo XIX. Para ello se recogerán y caracterizarán en diferentes tendencias historiográficas los trabajos más representativos sobre esta temática. Se intentará superar la rigidez propia de todo ejercicio de elaboración de patrones ideales y abstractos mediante la especificación de los planteamientos y aportaciones de los autores más relevantes de cada una de ellas. Como paso previo se hace necesaria una contextualización teórica para una mejor comprensión de las reflexiones subsiguientes. Podría definirse el liberalismo como una doctrina política construida en torno a la defensa y la garantía de las libertades individuales. Este lenguaje político implica una concepción moderna del hombre y de la sociedad fundada en las nociones de derechos individuales, igualdad ante la ley y separación de lo público y lo privado. ${ }^{5}$ En el ámbito estrictamente político, los principios de

\footnotetext{
${ }^{4}$ Con "modernidad" sólo quiero indicar un conjunto de ideas, valores, referentes y principios nuevos acuñados como consecuencia de las revoluciones liberales (la de independencia de Estados Unidos, la francesa y la española de 1810 ), que eran totalmente novedosos frente a los valores corporativos propios del antiguo régimen. Para una visión mucho más amplia y matizada, véase Guerra, Modernidad, 1992.

${ }^{5}$ El carácter moderno del liberalismo fue puesto de manifiesto en el famoso discurso de Benjamín Constant sobre la libertad de los antiguos y de los modernos, pronunciado en París en 1819, que tanto eco encontró a un lado y a otro del Atlántico. Constant, Libertad, 2002. Sobre el resto de los aspectos definitorios del liberalismo, véase el estudio de Gray, Liberalismo, 1992.
}

respeto y garantía de la libertad individual lo llevan a preconizar un aparato estatal de reducidas dimensiones, con atribuciones y competencias restringidas, que permita el libre ejercicio de las iniciativas privadas; al mismo tiempo, defiende la necesidad de establecer mecanismos de control del poder que prevengan de abusos y de arbitrariedades, y para ello aboga por la construcción de un armazón constitucional que fije los parámetros y alcances de su actuación, así como por la elaboración de una legislación que sea la que regule el proceso de toma de decisiones. En el siglo XIX en América Latina, los liberales vincularon estrechamente este lenguaje con los conceptos de democracia y de progreso, ${ }^{6}$ aunque ni una ni otro sean imprescindibles para su realización. ${ }^{7}$

El debate en torno al liberalismo mexicano fue retomado por Jesús Reyes Heroles, en un trabajo que supuso la culminación de una tradición historiográfica iniciada en el mismo siglo XIX por los creadores del Estado mexicano y en cuyo surco el estadunidense Charles Hale ha elaborado propuestas generadoras de nuevos debates. Ambos forman parte de la primera corriente historiográfica que aquí será definida y que se caracteriza por la ausencia de cuestionamientos acerca de

${ }^{6}$ Sobre este asunto se ha escrito mucho desde diferentes inquietudes. Desde planteamientos genéricos, destaca el ya clásico texto de Bury, Idea, 1971. Atendiendo a la casuística concreta de América Latina, el debate acerca de las consecuencias de la asunción de este paradigma por parte de las elites como principal objetivo político se ha desarrollado principalmente en las propuestas de Burns, Pobreza, 1990, y Morse, Espejo, 1982.

7 Tanto Gray como Bobbio abundan en estas concepciones. Gray, Liberalismo, 1992. Bobbio, Liberalismo, 1992. 
la existencia del liberalismo en México. Los demás trabajos recogidos en esta panorámica se agrupan en otras tres tendencias, desde las que se ha intentado, de maneras diferentes, analizar, primero, si realmente se produjo o no un tránsito a la modernidad política y, segundo, si la respuesta es afirmativa, de qué manera se hizo. Cada una de estas propuestas está en gran medida condicionada por dónde ubica la problemática específica de la modernidad. En este sentido, y desde una perspectiva social, tanto la segunda como la tercera concentran el análisis en un elemento muy concreto, el de la gobernabilidad, en la medida en que se preocupan por comprobar si fue posible o no lograr la consolidación de unas instituciones garantes del orden, la paz social y, sobre todo, la estabilidad política del país. Desde la historia política, la cuarta propuesta, por su parte, analiza el proceso de gestación de los nuevos principios en México y su implantación como los fundamentos de un nuevo sistema que afectó a las estructuras políticas del país pero también mentales de su población; defiende que este diálogo entre lo nuevo y lo viejo originó en México un tipo determinado de modernidad, y más concretamente, de liberalismo.

Como se verá a lo largo de esta exposición, el primer modo interpretativo (Reyes Heroles y Hale) básicamente se concentra en describir la formación y el desarrollo a lo largo del siglo XIX de un liberalismo en México, de cuya existencia ni $\tan$ siquiera duda. El segundo (Escalante), sin embargo, defiende la idea del fracaso de la instauración del Estado liberal en México; parte de posturas presentistas, desde las que analiza el siglo XIX, y por ello considera que la ausencia de una democracia totalmente representativa hace pensar que en México no se produjo realmente su asentamiento. Considera que también fracasó la consolidación de un poder central único, máxima expresión de la soberanía popular. Construye su argumentación en torno a las ideas de oposición (en diferentes niveles: la elite frente a la mayoría de la población, el discurso frente a la realidad, las constituciones frente a la práctica política), de imposición (no de intercambio) y de fracaso (en el intento de establecer un poder central sobre los poderes particulares). La tercera corriente historiográfica ("liberalismo popular"), por su parte, considera que sí se logró construir un Estado liberal eficaz, y que ello fue gracias a la pervivencia de espacios de libertad y autonomía por parte de los actores sociales locales frente a una supuesta expansión del poder central. Con una visión más histórica, su análisis atiende más a la contingencia, y por ello le interesa especialmente la dinámica del intercambio y de influencia entre la periferia y el centro, esto es, los poderes locales y el gobierno central. La cuarta (Annino, Guerra y Rodríguez) no está preocupada por el tema de la gobernabilidad, sino que más bien plantea el problema desde su propia raíz, la política. Desde la revisión de los planteamientos tradicionales acerca de los procesos independentistas, amplía la perspectiva de análisis hacia el estudio de la transformación de la mentalidad, de los referentes simbólicos y conceptuales de la sociedad y su adscripción a un marco referencial más propio de la modernidad.

Por último, veremos cómo todos estos estudios han centrado su análisis en los sectores políticos que más rápidamente se modernizaron, en ocasiones con una 


\section{SECUENCIA}

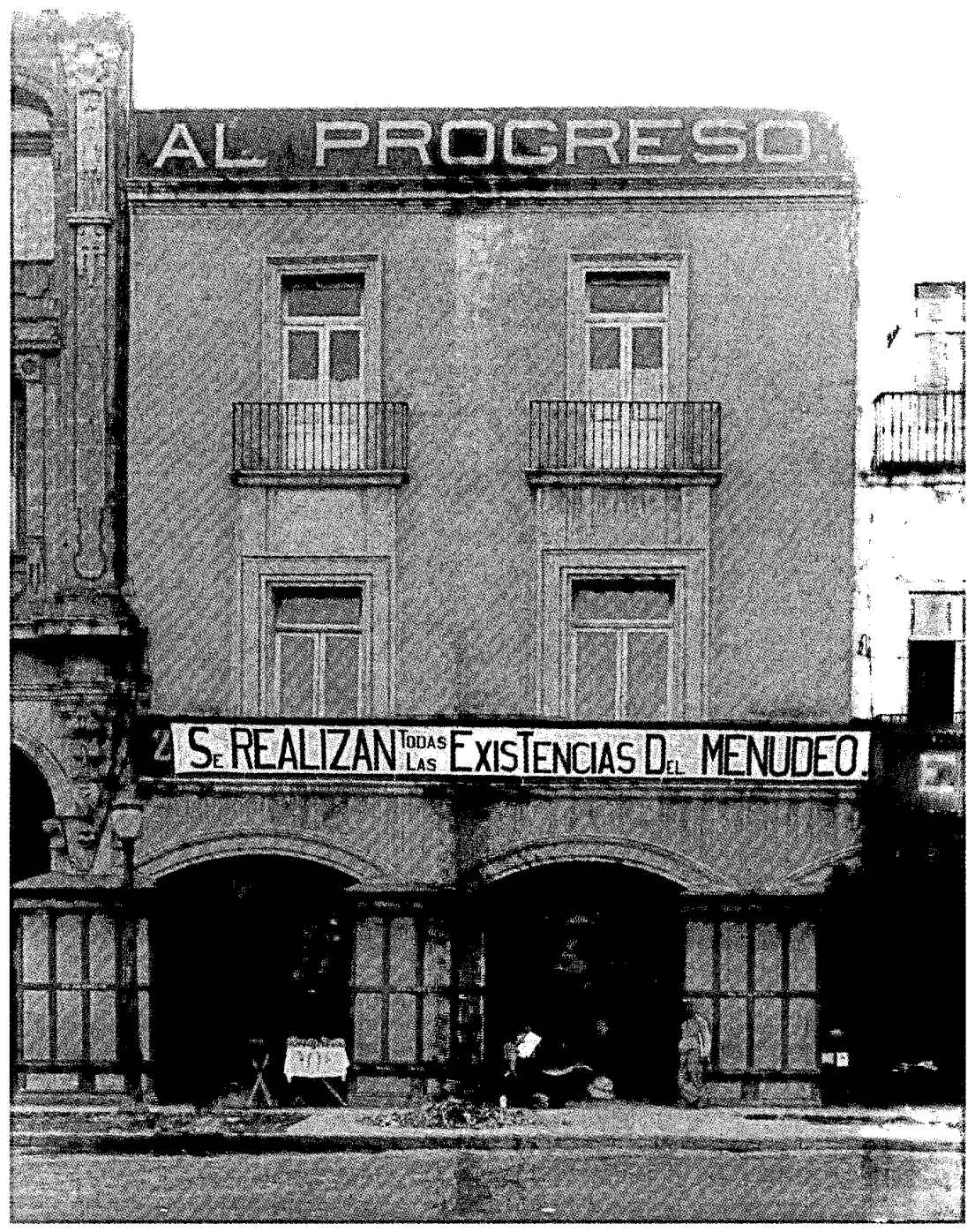


visión un tanto lineal, evolutiva y determinista del proceso histórico, obviando en gran medida las contribuciones de otros grupos, como los conservadores, por considerarlas de manera genérica irrelevantes o retrógradas. Sin embargo, resulta innegable el papel que este colectivo desempeñó en la política del siglo XIX mexicano, no sólo por lo que atañe a su participación en la constitución de un nuevo mapa político, sino también por sus aportaciones puntuales al debate teórico y a la realidad política del país. En este sentido, resultaría de gran utilidad, para conocer con mayor precisión y amplitud el desarrollo político de México, superar los prejuicios que en cierta medida han supuesto el arrinconamiento de una visión dialéctica y posibilista del devenir político del siglo XIX. ${ }^{8}$

Antes de entrar en materia, sin embargo, es imprescindible señalar algunos de los principales problemas de carácter metodológico con los que se enfrenta un ensayo de las características del presente. El deseo de recoger tan numerosa literatura en un número reducido de tendencias hace difícil, por un lado, presentar cada uno de los estudios o de los autores que han trabajado sobre la materia y ge-

${ }^{8}$ Es necesario mencionar los escasos pero magníficos trabajos existentes sobre el conservadurismo mexicano en el siglo XIx. Quizás el más antiguo, pero también el de mayor entidad, es el de Noriega, Pensamiento, 1972. Este estudio vendría a ser el paralelo de Reyes Heroles para el pensamiento conservador. Recientemente ha aparecido una recopilación de artículos bajo la dirección de Morales y Fowler, Conservadurismo, 1999. Igualmente, no se pueden olvidar los trabajos de Connaughton sobre esta materia, especialmente para los casos concretos de Puebla y de Guadalajara, algunos de ellos recogidos en Connaughton, Dimensiones, 2001. nera, por otro, una rigidez en la caracterización que a menudo impide una aproximación más detallada y minuciosa a la gran variedad y especificidad tanto de unos como de otros. El primer problema se ha intentado superar mediante la mención únicamente de aquellos estudios o autores más significativos bien por haber sido ellos los generadores o difusores de cada tendencia, por haber aportado una visión más completa acerca de ésta, o bien por haber alcanzado una mayor proyección pública; el segundo obstáculo se ha pretendido solventar mediante la incorporación de aquellos análisis que, siendo relevantes por diferentes motivos, sirven, además, para matizar la descripción general de la corriente en la que se inscriben. Por último, las notas a pie de página ayudan en cierta medida a paliar ambas deficiencias.

\section{CONTINUIDAD Y ACTUALIZACIÓN DEL DEBATE DECIMONÓNICO: DESARROLLOS DEL LIBERALISMO MEXICANO}

Desde el momento de la entrada victoriosa del Ejército Trigarante se abrió un prolífico debate acerca del proceso de definición política del nuevo Estado mexicano que perduraría a lo largo de todo el siglo. Las numerosas tentativas de concreción de la forma de Estado y de gobierno más apropiadas para el país generaron un ámbito de discusión de importante contenido teórico en el que los principios liberales fueron echando raíces entre el grupo dirigente. La primera tendencia historiográfica que aquí se presenta se caracteriza por continuar con este debate iniciado por los pensadores del siglo XIX. Sus máximos exponentes son Jesús Reyes 
Heroles y Charles Hale. Ni uno ni otro se cuestionan la existencia del Estado liberal en México, sino que se limitan a describir el proceso de creación y definición del mismo. Reyes Heroles, influido por el materialismo histórico, recogió y formalizó en su obra una serie de tópicos historiográficos que habían sido gestados al hilo de los debates del siglo XIX, y que no sólo han tenido una gran trascendencia en la producción historiográfica posterior sino que también han desempeñado un papel activo fundamental en la conformación de la identidad nacional mexicana; Charles Hale, por su parte, aporta una visión desde la historia de las ideas políticas, analizando el proceso de construcción e incorporación de las mismas en el ámbito estrictamente político.

El trabajo de Jesús Reyes Heroles constituye, aún hoy, y a pesar de las numerosas críticas recibidas, la referencia fundamental y básica para cualquier estudioso interesado en el México del siglo XIX. Su consideración de la independencia, la reforma y la revolución como los momentos históricos significativos y fundadores de la nación mexicana se inscribía en una concepción continuista, lineal, evolutiva y meliorativa de la historia propia del pensamiento liberal, ${ }^{9}$ no exenta, por cierto, de implicaciones políticas. ${ }^{10}$ En su

9 Sobre la concepción liberal decimonónica de la historia, entre otros, véase Gray, Liberalismo, 1992, pp. 28-34. Por otro lado, tal y como este autor define el liberalismo reformista de 1911 , se puede caracterizar la producción de Reyes Heroles como una continuación de éste. Ibid., p. 58.

10 "En México, nuestros antecesores, las generaciones que forjaron este país, estaban muy conscientes de la continuidad de la historia. Sabían, y lo decían, que la historia es la política mirando hacia atrás, como la estudio fijó algunas de las ideas más visitadas no sólo en el ámbito estrictamente académico, sino también fuera de éste." La primera es la consideración del establecimiento exitoso del Estado liberal en México, al que define como el proyecto de una clase media, baluarte de los derechos individuales y deseosa de promover el progreso; la segunda es la identificación del liberalismo con el triunfo de éste, logrado gracias al apoyo popular, esto es, con las Leyes de Reforma y la formulación de que éstas, además, sirvieron como "motor del cambio de la sociedad" (fe en que la legalidad promovió el cambio); la tercera, la identificación del momento del triunfo del liberalismo con el del nacimiento de la identidad nacional mexicana, con lo que se vinculan esencialmente ambos fenómenos; la cuarta, la identificación del liberalismo principalmente

política es la historia mirando hacia delante $|. .$.$| Por$ ello, los que hicieron la teforma se sentían, y con tazón, continuadores de los que lograron la independencia, de los que venían de la insurgencia", Reyes Heroles, recogido en Carrasco, Ideario, 2000, p. 46.

$1 "$ Algunas de ellas ya habían sido formuladas por Cosío en los años cincuenta, en Histuria, 1955, como es la de la consideración de la Constitución de 1857 como el primer intento por modernizar México; es con Reyes Heroles cuando se inscriben en una visión más amplia que abarca todo el siglo XIX. Reyes Heroles caracteriza el periodo que llega hasta 1867 como de búsqueda exclusiva de la libertad política, mientras que al régimen de Porfirio Díaz, de lucha por el progreso económico. Éste, por cierto, es otro de los tópicos más recurrentes en la historiografía porfiriana. Para conocer más acerca de la producción de Cosío puede ser útil, Cien, 1999. Una buena síntesis del pensamiento historiográfico acerca del liberalismo mexicano y de las similitudes y diferencias entre uno y otro, así como la vinculación de sus escritos con la política del momento se encuentra en el artículo de Hale, "Mitos", 1997, pp. 821-837. 
como el proceso de secularización de la esfera política (separación Iglesia-Estado) $y$, por consiguiente, la definición de la nacionalidad mexicana en clave secularizante; ${ }^{12}$ y la quinta, una comprensión evolucionista del proceso histórico como si se tratara de un desarrollo en el que en cada momento se fueran sumando nuevos atributos hasta constituir el momento actual: el liberalismo ilustrado mexicano dio lugar al democrático y éste, al social. Su trabajo, en definitiva, presenta el siglo XIX como la génesis de la revolución de 1910 y en cuanto tal, carente de autonomía y entidad propia. ${ }^{13}$

En esa misma línea de una historia heredera y continuadora de las grandes visiones de los hombres del siglo XIX, y con una gran agudeza en el análisis de las ideas políticas, se encuentran las aportaciones de Charles E. Hale, quien se ha centrado en desentrañar tanto la gestación y la difusión de los principios liberales ${ }^{14}$ como su pervivencia y su transformación a lo largo del siglo XIX. ${ }^{15}$ En este ámbito, ha sido uno de los pioneros en poner de relieve la complejidad del proceso de definición de los pensamientos liberal y conservador, afinando cronológicamente el momento y la naturaleza del nacimiento de los partidos políticos que los representaban, así como los proyectos que cada uno defendía. ${ }^{16}$ Analiza detalladamente de qué fuentes se nutrieron los ideólogos

\footnotetext{
${ }^{12}$ Un buen ejemplo de la vigencia de estos presupuestos puede verse en Staples, Dominio, 1989.

${ }_{13}$ Reyes Heroles, Liberalismo, 1974.

${ }^{14}$ Hale, Liberalismo, 1999.

${ }^{15}$ Hale, Transformation, 1989.

${ }^{16}$ En esta misma línea, Vázquez, "Liberales", 1997, pp. 153-175.
}

del XIX, y en este sentido ha mostrado la influencia del pensamiento ilustrado español, de las formulaciones de Benjamin Constant y del utilitarismo de Jeremy Bentham en las propuestas de los primeros liberales mexicanos. El estudio del desarrollo del liberalismo a lo largo de todo el siglo lo ha llevado a fijar elementos de continuidad, concretamente, entre el utilitarismo y el positivismo, cuya reconciliación, a pesar de lo que teóricamente cabría esperar, asegura Hale, pudo darse en el momento del porfiriato como consecuencia de su empresa de consenso materializada en una praxis liberal conservadora. Así, insiste, desde 1867 el liberalismo se constituyó en un mito unificador que imposibilitaba no sólo la creación de grupos defensores de los principios conservadores, sino incluso la creación de un sistema de partidos con propuestas diferentes. Esta continuidad doctrinal fue acompañada de otra de corte sociológico: la del conservadurismo social criollo, ${ }^{17}$ que constituyó un punto de encuentro fundamental entre liberales y conservadores, especialmente en aquellos momentos en que se sintieron amenazados por el indio (guerras de Castas). Con ello Hale rebate una de las principales tesis de Reyes Heroles al evidenciar cómo, a pesar de los desarrollos posteriores de la política social mexicana, en la era de Mora ni las doctrinas liberales de individualismo ni las de igualdad generaron posturas pro democráticas. ${ }^{18}$

La exquisita identificación que Jesús Reyes Heroles hace de los principales temas a los que el liberalismo mexicano

\footnotetext{
${ }^{17}$ Hale, Liberalismo, 1999, p. 306.

${ }^{18}$ Ibid., p. 254.
} 
intentaba dar respuesta y la magnífica presentación de Hale a los pensadores y políticos mexicanos no sólo como conocedores sino como activos participantes en los debates que estaban teniendo lugar entonces en Occidente acerca de los principios teóricos y prácticos del liberalismo han marcado muy positivamente todo el desarrollo posterior de la historiografía sobre el liberalismo mexicano. En este sentido, sus trabajos son ya clásicos y pueden considerarse como lecturas imprescindibles en la iniciación de todo historiador mexicanista.

Aun reconociendo este débito de los nuevos trabajos a los de Hale y Reyes Heroles es necesario, sin embargo, subrayar la gran renovación que han experimentado este tipo de estudios en los últimos años; la transformación de la historia social y el auge de la historia cultural y política los han reorientado hacia nuevos planteamientos, perspectivas y temas de trabajo, a pesar de la pervivencia, a menudo no del todo reconocida, de presupuestos del materialismo histórico. La mayoría de ellos se ha planteado en torno a, por un lado, temas como la ciudadanía, la soberanía, la legitimidad y la representación política y, por otro, la construcción y difusión de imaginarios y símbolos que constituyeron el contexto de comprensión y aprehensión de los nuevos principios, así como la relación de éstos con los viejos. De la misma manera, los análisis que toman como referencia el territorio de todo el Estado empiezan a convivir y dialogar con los dedicados al ámbito regional y local. Como veremos, a menudo los mismos autores participan en varios de los modelos como consecuencia del desarrollo de su investigación.
PROPUESTAS DESDE LA HISTORIA SOCIAL AL DEBATE HISTORIOGRÁFICO SOBRE LA EXISTENCIA DEL LIBERALISMO MEXICANO

El fin de los grandes relatos, ${ }^{19}$ cuya máxima expresión emblemática ha sido la caída del muro de Berlín, ha supuesto una crisis de los paradigmas interpretativos que ha afectado a numerosos ámbitos, entre ellos, el del conocimiento. En este sentido, la nueva situación ha forzado un replanteamiento epistemológico que las ciencias sociales, y por lo tanto también la historia, han tenido que realizar para reubicar sus objetivos, presupuestos, métodos y ámbitos temáticos. Esta transformación ha afectado especialmente a la historia social, que había sido la reina descle fines de la década de los sesenta, consorte, además, de una historia económica fundada en los principios del materialismo histórico. En este sentido, el interés por las cuestiones y los desarrollos políticos no sólo ha supuesto una recuperación del protagonismo de la historia política, sino también una reorientación de la historia social hacia los asuntos relacionados con ella. Así es como se explica el nuevo interés suscitado por temas como la ciudadanía y la representación política. Sin embargo, la vigencia de los presupuestos estructuralistas a menudo sólo ha posibilitado la incorporación de este nuevo lenguaje sin llegar a plantear una revisión en profundidad que permita superar las explicaciones dialécticas de la sociedad.

Las próximas dos corrientes historiográficas que aquí serán delineadas comparten una serie de aspectos que justifican su presentación conjunta en este texto: por un lado, ambas se cuestionan acerca

\footnotetext{
${ }^{19}$ Lyotard, Condición, 1987.
} 
del éxito en el proceso de consolidación del Estado liberal en México (aunque cada una llega a una respuesta diferente) y, por otro, las dos buscan en esta historia social reformulada las claves de lectura que les permitan extraer alguna conclusión sobre la materia. El representante más conocido de la segunda es Fernando Escalante, quien en 1992 publicó el libro Ciudadanos imaginarios, ${ }^{20}$ de gran difusión no sólo en ámbito mexicanista, que venía a recoger, bajo una aparente nueva perspectiva, una serie de aspectos tratados hasta entonces de forma parcial por trabajos en gran medida herederos de paradigmas sociológicos que ponían el énfasis en factores estructurales, como el materialismo histórico o la teoría de la dependencia. La tercera surgió tras la superación de los planteamientos marxistas en el seno de la historia social y se ha dado en llamar "liberalismo popular"; buena muestra de los autores que han trabajado desde esta perspectiva así como de la variedad de sus temas puede encontrarse en El liberalismo mexicano, cuaderno publicado en 1993.

\section{Una interpretación negativista}

de la bistoria de México: el supuesto

fracaso del liberalismo mexicano

La segunda tendencia historiográfica rebate severamente los presupuestos en los que se fundan las aportaciones de Reyes Heroles, en la medida en que afirma que la implantación del liberalismo en México fue un fracaso que nunca llegó a institucionalizarse, y que a lo sumo se trató de un discurso legitimador que la elite del

\footnotetext{
${ }^{20}$ Escalante, Ciudadanos, 1999. La primera edición de este trabajo apareció en 1992.
}

siglo XIX usó para mantener su dominación sobre el resto de la población.

Basándose mayoritariamente en estudios de la época porfiriana y generalizando sus conclusiones para todo el siglo, estos trabajos defienden que el liberalismo, al tratarse de una ideología importada, no era materializable en una realidad tan ajena a aquella en la que y para la que había sido formulada. En la mayor parte de ellos, retomando una dicotomía elaborada por ciertos planteamientos del siglo XIX, ${ }^{21}$ subyace el presupuesto de la existencia de dos culturas, la sajona y la latina, de las cuales tan sólo la primera se considera capaz de generar unas prácticas políticas que respondan con exactitud al modelo liberal, y ello como consecuencia de un proceso histórico de separación de lo público y lo privado, lo religioso y lo político iniciado de forma exitosa en la edad moderna. Frente a ella el mundo hispánico, y en este caso México, aparece caracterizado como intrínsecamente incapaz de incorporar dichas prácticas, ya sea como consecuencia de unos malos hábitos adquiridos durante el periodo de la Nueva España ${ }^{22}$ o como la postura más extremista, como una incapacidad natural consustancial a lo que, de manera esencialista y

\footnotetext{
${ }^{21}$ Recuperan esta dicotomía entre el espíritu latino y el anglosajón pero sin, aparentemente, hacer una valoración moral sobre cada una de las culturas, cosa que sí se hacía en el XIX, tal y como explica Litvak, Latinos, 1980.

${ }^{22}$ Esta culpabilización de la época de la dominación española tomó gran difusión como consecuencia del estudio elaborado por orden del secretario de Estado estadunidense Henry Kissinger, quien pretendía demostrar que el mal latinoamericano se debía a la herencia colonial y con ello garantizar su protagonismo en esta región.
} 


\section{SECUENCIA}

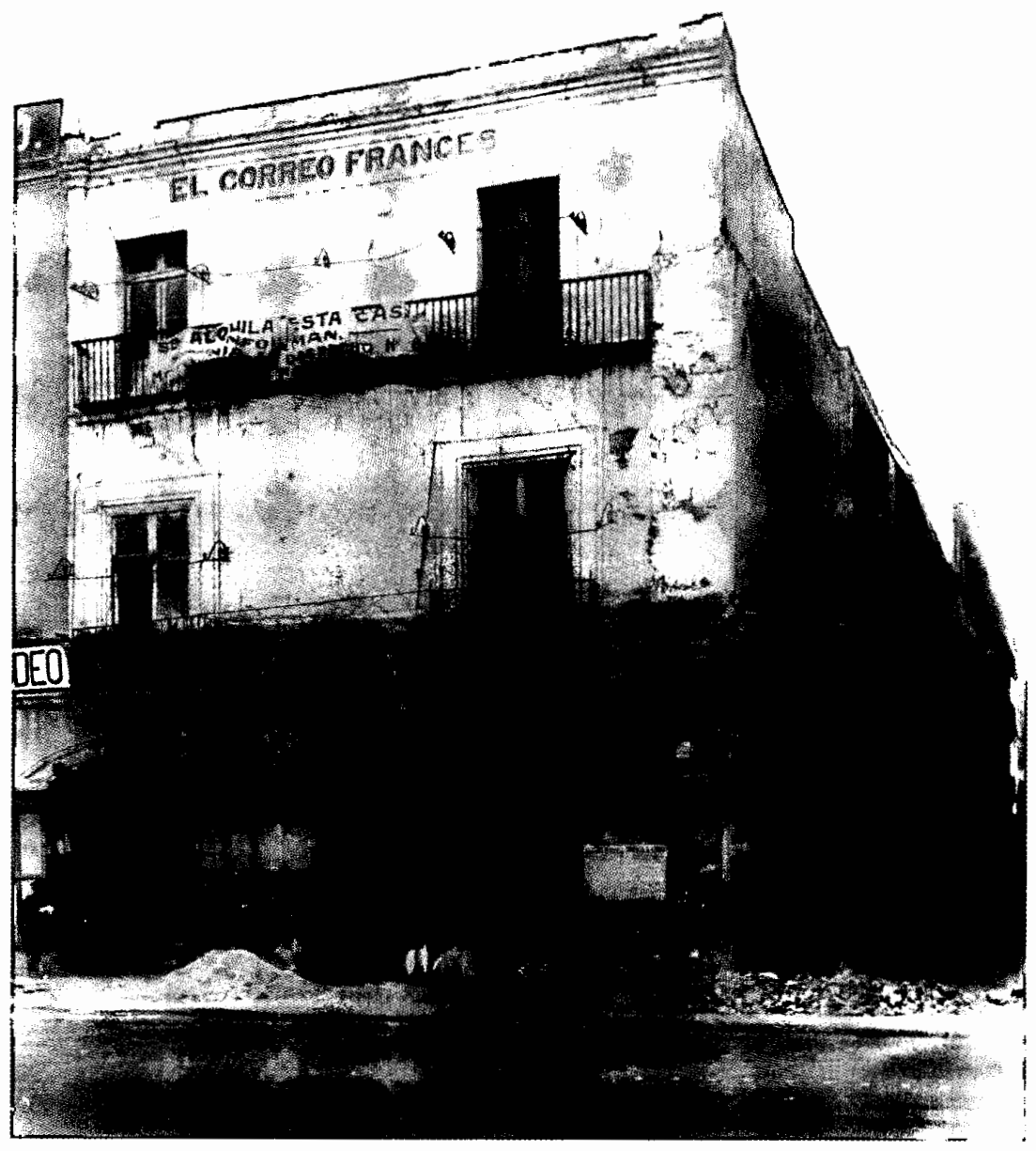


no poco ambigua, se denomina tradición autóctona, mezcla de la mesoamericana y la española. Se plantea no tanto una jerarquización de las culturas, sino, más bien, la existencia de dos cosmovisiones manifiestamente diferentes e irreconciliables; esta incompatibilidad, argumentan, al ser obviada por las elites dominantes produjo el fracaso de la modernización mexicana. De ahí a formular abiertamente que todos los problemas que existen en la actualidad se podrían haber evitado si se hubiera elaborado un proyecto diferente más acorde con una tradición ibero-africano-mesoamericana vernácula, idealizada y sin acabar de definir concretamente, sólo hay un paso. ${ }^{23}$ Es precisamente su proyección presentista, desde los problemas del México del siglo xxi, la que les devuelve una imagen negativa de los logros mexicanos en su proceso de modernización a la europea, sin permitirles atender a los alcances obtenidos de manera progresiva en esta dirección, no sólo desde una perspectiva económica y social, sino también desde la propia dinámica de representación y participación política. ${ }^{24}$

La mayor parte de los estudios históricos que constituyen esta corriente explican el siglo XIX como una continuación de ciertos tópicos historiográficos de la historia colonial que recientemente han

${ }^{23}$ Inciden en que el caso latinoamericano es, simplemente, diferente, y que por ello debía haber creado su propio modo de desarrollo. Ésta es una de las principales tesis defendidas en libros tan difundidos como el de Burns, Pobreza, 1990, o el de Bonfil Batalla, México, 1994.

${ }^{24}$ Para las dinámicas de inclusión y exclusión en los procesos de definición de proyectos nacionales en América Latina, véase Quijada, "Nación", 1994, pp. 15-51. sido superados. ${ }^{25}$ En este sentido, desde cualquier perspectiva o problemática, la mayor parte de ellos establece una suerte de división irreconciliable entre dos mundos: el de los criollos y el de los indígenas, que en la tradición del materialismo histórico se corresponderían con los dominantes y los dominados respectivamente. Ambas realidades son presentadas como compartimentos estancos, en gran medida inamovibles, inmutables y carentes de cualquier tipo de comunicación, especialmente en lo referente a las comunidades indígenas. A esa falla social le corresponde otra política que es la que hace que no existan vías de comunicación recíproca entre el Estado y la sociedad civil. ${ }^{26}$ Así, el primero es identificado con la defensa de los intereses de la elite y la segunda, como la mayoría de la población, que sólo puede asumir lo que le viene impuesto desde la autoridad política. Los principios liberales, sostienen, fueron apropiados y utilizados por esta elite para perpetuar un dominio y un control sobre la sociedad, legitimando su poder tradicional a partir de los nuevos ideales, pero sin incorporar realmente una nueva manera de concebir la política. Los ideales de libertad, igualdad, soberanía, ciudadanía y las prácticas de representación no eran sino ficciones, o para usar la expresión de Fernando Escalante, principios "imagi-

${ }^{25}$ Sirvan como buen ejemplo los capítulos de Urías Horcasitas dedicados al análisis de la cultura política española y novohispana desde la edad media. Urías Horcasitas, Historia, 1996, pp. 21-77.

${ }^{26}$ Esta visión dicotómica de la fractura entre sociedad civil y Estado fue ampliamente elaborada por los pensadores del xvill quienes, además, siempre consideraban que la primera era buena y el segundo, malo. Tal es como lo formula el mismo T. Paine. Recogido en Bobbio, Liberalismo, 1992, p. 22. 
narios", irreales; esto es, meramente discursivos en la medida en que únicamente cubrían con una pátina de modernidad prácticas tradicionales.

Precisamente de la mano del trabajo más conocido de Fernando Escalante, Ciudadanos imaginarios, libro relevante no sólo por la proyección pública que ha alcanzado sino también porque viene a constituir una propuesta sintetizadora que engloba particularidades o perspectivas que han sido desarrolladas de forma específica por otros autores, se intentará caracterizar con mayor precisión algunos factores que comparten la mayor parte de este tipo de estudios. Este texto defiende la tesis de que el intento de implantar una moral cívica en México fue un fracaso, lo que generó una fractura insuperable entre la sociedad y el Estado. En este sentido, considera que el principal problema político del México del siglo XIX fue el de fundar la autoridad del Estado liberal y democrático, pues aunque sí existía una formalidad jurídica, sin embargo, las costumbres políticas respondían más a los modos tradicionales del ejercicio del poder que a los nuevos principios republicanos e individualistas. Frente a un Estado incapaz de centralizar el poder se encontraba una sociedad con formas de poder y de orden propias y no estatales basadas principalmente en los vínculos personales y las negociaciones particulares. Así, el seguimiento social de las normas tenía que negociarse con los intermediarios (notables locales y funcionarios casi autónomos básicamente) que, por medio de lo que Escalante denomina la negociación de sus desobediencias, ${ }^{27}$ mantenían así sus privilegios y su poder. En definiti-

${ }^{27}$ Escalante, Cizudadanos, 1999, p. 111. va, "la sociedad producía sus formas de poder y orden no estatales, el Estado imponía su definición formal del orden político, y los intermediarios gestionaban la coherencia y la estabilidad". ${ }^{28}$ Por lo tanto, aunque sí existió un Estado, éste era débil, por lo que tuvo que recurrir al uso de los mecanismos informales (clientelistas, patrimoniales y corruptos) para ejercer el control político. El coste político que tuvo que pagar fue, continúa, el de no constituirse como democrático ni como liberal. Seguramente, Escalante no ofrecería una visión tan negativa de los logros del Estado mexicano si no partiera de una definición prejuiciada, presentista y ahistórica de la ciudadanía.

En esta misma línea historiográfica se encuentra un conjunto de estudios que se han dedicado a analizar las dificultades o la incapacidad del Estado mexicano por constituirse como un poder central expresión de la soberanía nacional y, por lo tanto, como única entidad a la que se debiera lealtad, por encima de la variedad de soberanías territoriales y corporativas existentes. Desde la perspectiva de la historia económica, Marcelo Carmagnani ha defendido con insistencia esta tesis, basándose principalmente en el análisis de la contribución económica que los poderes regionales hacían al poder central, y especialmente en la consideración que hacían de éstos más como una concesión que como una obligación; su trabajo postula la debilidad de este poder central sobre los regionales,${ }^{29}$ debilidad que se mostró igualmente, continúa Carmagnani y ahora desde la historia social, en su incapacidad para crear y difundir una moral cívica

\footnotetext{
${ }^{28}$ Ibid., p. 121.

${ }^{29}$ Carmagnani, "Finanzas", 1995.
} 
uniforme para todo el Estado y superadora de una visión localista de la misma, ${ }^{30}$ así como en la no incorporación de las nuevas clases emergidas al calor del crecimiento económico y social obtenido durante el porfiriato. ${ }^{31}$ En resumen, según Carmagnani, el pensamiento liberal en México perdió su capacidad innovadora y se convirtió en una ideología al servicio de la conservación de la política y del poder.

Según otras propuestas, algo similar ocurriría con la materialización del principio de soberanía popular en la medida en que el sistema de representación existente nunca cumplía las premisas del modelo ideal del Estado liberal y democrático: el sufragio, censatario, no era ni libre ni individual, sino que respondía más bien a un modo de participación política tradicional..$^{32}$ En este sentido, estudios como los de Marco Bellingeri presentan las elecciones como una estrategia mediante la cual las elites, activando los modos de participación política tradicionales, se presentaron como los grupos rectores elegidos según los nuevos principios de

${ }^{30} \mathrm{Y}$ ello debido a que los grupos locales se opusieron con el fin de mantener su poder frente al Estado. Incluyo este artículo en esta corriente y a pesar de la participación en él de Alicia Hernández Chávez, como se verá, una de las representantes de la tercera, en la medida en que en él se presenta esta siruación como una deficiencia del Estado central y no como una expresión más de la libertad de los ámbitos locales en su modo de proceder. Carmagnani y Hernández Chávez, "Ciudadanía”, 1999, pp. 371-405.

31 Carmagnani, "Libertad", 1995, p. 242.

${ }^{32}$ Una interpretación alternativa y novedosa acerca de los procesos de participación política en el siglo XIX puede verse en Irurozqui, Bala, 2000. Aunque este análisis trata sobre Bolivia, sin embargo, su propuesta puede servir como modelo para otros estudios de caso. la soberanía constituyente. ${ }^{33}$ Otras aportaciones consideran que las deficiencias del sistema empezaban incluso antes del intento de mejorar su materialización: los propios dírigentes del momento a menudo manifestaban una importante resistencia a la incorporación de los nuevos principios políticos, tal y como Beatriz Urías Horcasitas sostiene para el principio de igualdad. ${ }^{34}$

Por otro lado, la interpretación que defiende que el recurso de la elite al argumento político de modernización del país fue únicamente una estrategia para la defensa de fines de grupo y con la intención de someter a toda la sociedad tiene especial relevancia para el caso de un colectivo de gran repercusión simbólica en la sociedad mexicana: las comunidades indígenas. Obviando el análisis de los posibles modos de participación de estas comunidades en las decisiones estatales o federales $y$, por lo tanto, su voluntad y capacidad de incorporación a la nueva realidad política, este tipo de estudios básicamente las ha considerado, cuando más, sujetos pasivos receptores de unas medidas adoptadas por las elites que, además, tendían a reforzar su sometimiento. Junto a esta imagen también se las ha visto como renuentes a la modernización para evitar la pérdida de protecciones generadas durante la co-

33 Bellingeri, "Soberanía", 1995, pp. 65-91, y "Voto", 1995, pp. 91-121. Sus estudios son una muestra clara de la superposición de las tendencias historiográficas que aquí se están delineando; a pesar de la incorporación de las nuevas temáticas (elecciones, soberanía...) y perspectivas (la regional: Yucarán), sin embargo sus propuestas tienden a ratificar esa visión dialéctica y de liberalismo no conseguido propia de este segundo modelo.

${ }^{34}$ Urías Horcasitas, Historia, 1996. 
lonia. Esta interpretación responde a la ya mencionada visión dialéctica de la sociedad mexicana. La definición en clave étnica de lo que en otros ámbitos había sido la lucha de clases va acompañada de una victimización del indio que, a la larga, ha ocasionado una paradójica consecuencia: si por un lado se culpabilizaba a la elite de haber mantenido a las comunidades indígenas en un estado de atraso como consecuencia de la explotación y exclusión a la que habían estado sometidas no sólo durante los tres siglos de dominación española, sino también tras la obtención de la independencia, por otro, se presupone su incapacidad, su ignorancia o su falta de iniciativa para participar en el nuevo Estado liberal. ${ }^{35} \mathrm{~A}$ menudo se considera que forma un colectivo que nunca podría adaptarse a las necesidades del mundo moderno, ${ }^{36} \mathrm{e}$ incluso, en interpretaciones sumamente generalizadas se culpabiliza al Estado de actuar premeditadamente para finiquitar todo tipo de peculiaridad ocasionada por la pervivencia del indígena y de su comunidad; esta postura deviene generalmente en acusación, sin atender a que responde a un momento en el que el "paradigma de la homogeneidad" hacía que estas medidas no sólo fueran las practicadas por la mayor parte de

${ }^{35}$ Aunque menos común, también hay quien considera que la propia naturaleza de la comunidad indígena imposibilitaba a sus miembros a incorporarse al nuevo mundo liberal. Tal es el caso de González y González, Indio, 1996.

${ }^{36}$ En su primer trabajo, ya superado por él mismo, Guerra defendía que la elite no fue la responsable de que la sociedad no se modernizara, sino que más bien ésta no estaba preparada para asumir ni los principios ni las consecuencias de dicha modernización. Guerra, México, 1988. Esta visión ha sido muy modificada por el propio autor en trabajos posteriores. los Estados, sino incluso las deseables. ${ }^{37}$ Sin duda estas ideas se corresponden con una literatura idealizadora del indígena muy manipulada ideológicamente. ${ }^{38}$

\section{Una versión complaciente de las realizaciones del Estado liberal mexicano}

Todavía en el ámbito de esta nueva historia social heredera de planteamientos estructuralistas, pero con una visión más positiva de los alcances del liberalismo en México y, por lo tanto, defendiendo hipótesis contrarias a la anterior, se ha desarrollado una tercera corriente historiográfica conocida como "liberalismo popular". ${ }^{39}$ Todas sus propuestas coinciden en rebatir los planteamientos dualistas que fijan la idea de un reducto liberal ajeno al cuerpo social. ${ }^{40}$ La perspectiva local, además, ha posibilitado la concre-

${ }^{37}$ Para conocer algo más acerca de este paradigma y de su papel en la definición del pueblo soberano en los procesos de construcción de los Estados nación, $y$, en concreto para el caso argentino, véase Quijada, Bernand y Schneider, Homogeneidad, 2000.

${ }^{38}$ Ferrer Muñoz y Bono López, Pueblos, 1998. De gran difusión pero muy maniqueo en sus interpretaciones resulta el libro de Bonfil Batalla, México, 1994.

39 Uno de los primeros estudios desde esta perspectiva fue el realizado por Alicia Hernández para el caso de Anenecuilco. Una muestra de la variedad de autores y propuestas del llamado "liberalismo popular", puede encontrarse en Annino y Buve, $L i$ beralismo, 1993. Annino, en el estudio introductorio, considera que los primeros trabajos que inauguraron esta corriente fueron los de Knight, "Liberal ismo", 1985, pp. 59-91; Brading, "Liberal", 1979, pp. 2745, y Thomson, "Popular", 1991, pp. 265-292. En esta misma corriente puede incluirse todo un elenco de estudios con resultados tan diversos como, por ejemplo, el de Mallon, Peasant, 1995.

40 Annino, "Nuevas", 1993, pp. 5-13. 
ción de los escenarios y de este modo atender a la interacción de diferentes factores en el análisis, dando lugar a una nueva pregunta: ¿cómo y cuándo se originó el encuentro entre el liberalismo y los pueblos? Sus estudios observan cómo se construye la nación desde la periferia hacia el centro, ${ }^{41}$ no sólo geográfico sino también en cuanto a las jerarquías administrativas; se habla más de un intercambio que de una dominación. De la misma manera, estos trabajos comparten un mayor enfoque histórico que el caso anterior, por lo que entienden el proceso de creación del Estado liberal como un desarroIlo paulatino, progresivo y contingente, que parte de unas estructuras tradicionales que poco a poco se van modificando, adaptando o perpetuando. La atención a los casos concretos no sólo ha puesto de relieve la capacidad de actuación y de intervención de los pueblos en la configuración política del país, y su protagonismo en la definición del liberalismo mexicano, sino que también ha aportado una mayor dosis de verosimilitud y de complejidad a aquellas interpretaciones que únicamente trataban de presentar una realidad que no se adecuaba a un modelo teórico, dando cabida explicativa incluso a situaciones que podrían resultar a primera vista paradójicas. En definitiva, todos estos análisis confirman el éxito en el proceso de construcción del Estado liberal, aunque reconociendo la existencia de ciertas peculiaridades específicas. $\mathrm{Al}$ igual que en el caso anterior, sin embargo, es necesario resaltar cómo muchos estudios, pese a tratar de incorporar un utillaje novedoso, en realidad sólo tienden a ratificar ideas preconcebidas y elaboradas dentro del mate-

${ }^{41}$ Ibid., p. 10. rialismo histórico: de ahí derivan las contradicciones de algunos de los trabajos en sus presupuestos más básicos.

Los nuevos temas de interés se centran en el municipio, la milicia nacional, el patronazgo y las elecciones puesto que se considera que éstos fueron los instrumentos que permitieron a las poblaciones rurales conocer, incorporar y en gran medida modificar los principios liberales. Ha sido precisamente uno de los trabajos versados sobre el papel del municipio en la propagación y definición del liberalismo en México el que mayor difusión y repercusión ha tenido incluso fuera del ámbito estrictamente académico. Publicado en 1993, Alicia Hernández Chávez lo escribió con el fin de hacer frente a esa

visión denigrante de nuestra tradición política que destaca los lazos autoritarios no liberales y caracteriza al liberalismo como una concepción de las elites que nunca permeó a la sociedad y que por lo tanto nada puede enseñar a nuestro presente que afanosamente se proyecta hacia la democracia. ${ }^{12}$

Partiendo de la consideración del liberalismo y del republicanismo como dos lenguajes políticos parcialmente confluyentes que conforman no sólo un cuerpo doctrinario sino también una práctica política difundida socialmente, ${ }^{43}$ su análisis

${ }^{42}$ Hernández Chávez, Tradición, 1993, p. 12.

${ }^{43}$ 1bid. La versión del republicanismo presentada por Alicia Hernández no está suficientemente precisada, de tal modo que una precipitada lectura de su libro puede dar lugar a una identificación de esta tradición política con el pensamiento y la práctica liberal. Acerca de las diferencias entre estos dos lenguajes políticos, véase Colom, Razones, 1998, pp. 69-84. 


\section{SECUENCIA}

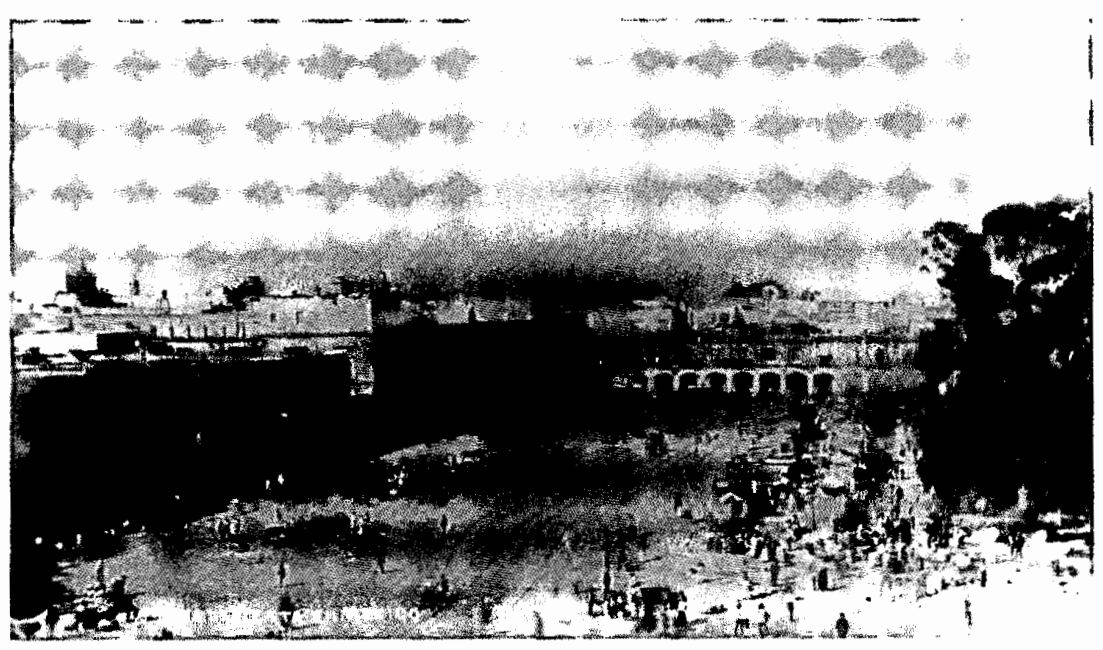


pretende describir cómo los diferentes actores sociales traducían en la vida cotidiana las normas institucionales y las políticas del gobierno, con el fin de captar la manera en que se dio vida a la interacción entre ciudadanía y gobierno. ${ }^{44}$ Así, concluía que

la ciudadanía organizada no fue una noción abstracta o imaginaria sino una realidad concreta que caló profundamente en la conciencia colectiva; que a partir de sus organizaciones desarrolló el ejercicio práctico del quehacer político y que en el proceso de elegir y vigilar el sufragio y a los electos, configuró una concepción de la representación política que es el fundamento de la gobernabilidad. $^{45}$

De esta manera, aquellas fracturas que el modelo de Escalante presentaba entre la sociedad y la acción política quedan aquí subsanadas mediante la descripción de prácticas socialmente difundidas de participación en la formación de la voluntad colectiva y en la elección de los representantes políticos. Con ello, pierde sentido igualmente aquella concepción del liberalismo como un discurso generado por las elites para legitimar su dominio sobre la sociedad: fue la empresa colectiva del pueblo y de la elite la que hizo triunfar la revolución liberal. De hecho, su interpretación viene a consolidar el mito de la reforma liberal como el momento fundacional de una cultura política moderna que encontrará su máxima culminación en la revolución de 1910-1920; a partir de ésta el país se abre a la contemporaneidad. Especialmente llamativas re-

\footnotetext{
${ }^{44}$ Hernández Chávez, Tradición, 1993, p. 13.

45 Ibid., p. 14.
}

sultan las coincidencias de su modelo con el de Reyes Heroles que ya vimos, en la identificación y secuenciación de los momentos fundacionales de la nación mexicana (independencia, reforma y revolución), generadoras de tres tradiciones (la republicana, la liberal y la social respectivamente) que se van acumulando armoniosamente a lo largo del desarrollo histórico de México. En este sumatorio aparece un momento de desaceleración (el porfiriato) que necesariamente será reconducido gracias a la revolución. Si en el trabajo de Reyes Heroles se consideraba que el ordenamiento jurídico, en especial la constitución (y más concretamente su promotora, la clase media), había generado el cambio social, en el de Alicia Hernández fue el municipio, como institución que articula el entramado político.

Esta propuesta, sin embargo, no llega a cumplir su propósito. En realidad no demuestra cómo tras la obtención de la independencia se forma una cultura política que difundió los principios de ciudadanía, y ello es debido a que únicamente restringe el análisis al estudio del municipio como institución. Esto ocasiona dos deficiencias. Por un lado, sobredimensiona la capacidad de las instituciones en la generación de nuevas prácticas políticas al presentar al municipio, eje de la articulación política de la vida local, como el productor y difusor entre la población de la nueva manera de concebir la política, y en definitiva, los principios y hábitos de la ciudadanía, y, por otro, presenta la negociación que éste hace con instancias superiores (la región, el estado, la federación) en la defensa de su autonomía como el único campo en el que se dirime en la práctica la lucha por la clefensa de los derechos de los ciudadanos. 
En realidad su comprensión de la cultura política es ciertamente reduccionista, puesto que ésta incluye otra serie de factores además de las instituciones, como, entre otros, la participación en las milicias nacionales, la creación de una opinión pública o el propio desarrollo de las prácticas electorales y de representación.

También desde una perspectiva local, pero atendiendo a una zona geográfica concreta, la de Puebla, Guy P. C. Thomson ha estudiado el proceso de definición y apropiación por parte de las comunidades de los principios liberales, llegando a la conclusión de que para que el pueblo pudiera disfrutar efectivamente de ciertas garantías liberales era imprescindible la existencia de tres condiciones: el patronazgo por parte de actores políticos poderosos por encima del poder local, el poder colectivo de la guardia nacional y la neutralización de la influencia ideológica de la Iglesia católica. ${ }^{46}$ Otros historiadores han centrado su labor en temáticas más específicas, como Alan Knight, en la milicia nacional, o Raymon Buve, en el patronazgo. En este sentido, el primero vincula la introducción del liberalismo con la necesidad de recurrir al reclutamiento de la población para participar activamente en las guerras frente a Estados Unidos, en la de Reforma y en contra del imperio de Maximiliano. De este modo, al convertirse en una ideología activa, de movilización popular, permitió que diversos grupos se apropiaran de estos principios. De esta relación entre realidad y teoría salieron diferentes modos de comprensión del liberalismo, que van desde el liberalismo popular (propio de los campesinos), pa-

${ }^{46}$ Thomson, "Bocasierra", 1993, pp. 121-141, y “Movilización”, 1987, pp. 592-615. sando por el constitucionalismo de la clase media urbana, hasta un liberalismo centralizador desarrollista que surgió con el porfiriato. La participación en las contiendas bélicas no sólo hizo que la población adquiriera conocimiento del liberalismo, sino que además permitió que las comunidades mantuvieran cierta autonomía política y económica. Quizá una de sus aportaciones más relevantes es la demostración de la existencia de revueltas campesinas para conservar el orden liberal, especialmente durante el porfiriato. ${ }^{47}$ Por su parte, Raymond Buve ha mostrado la insuficiencia del patronazgo, entendido como mecanismo de mediación y de integración política rural, ante el desarrollo económico experimentado, situación que generó una movilidad social que llevó a muchos clientes a salirse de sus redes tradicionales. ${ }^{48}$

En la medida en que las corrientes historiográficas aquí presentadas son estereotipos, dificultan la catalogación de trabajos que comparten, por diferentes motivos, características propias de más de una de ellas. Esto a menudo se puede explicar porque, tal y como han sido definidas, la tendencia negativista y la complaciente comparten un sustrato estructuralista, y porque algunos historiadores inician la investigación desde unas ideas preestablecidas que luego confirman con el estudio de caso concreto. Sirva como ejemplo Brian R. Hammett, quien sostiene que fue precisamente la debilidad del Estado lo que permitió la intervención de las masas en la política, de tal manera que presenta a ésta no sólo como el ámbito en el que las diferentes facciones de

\footnotetext{
17 Knight, "Liberalismo", 1985, pp. 59-91.

${ }^{18}$ Buve, "Transformación", 1993, pp. 173-176.
} 
la elite lidiaban sus diferencias, sino que "al contrario, las acciones de grupos sociales más allá de la elite podían retrasar o frustrar la realización de los objetivos de los gobernantes"; ${ }^{49}$ en este sentido, encuentra una estrecha relación entre las presiones de los grupos etnosociales y los cambios políticos.

En cualquier caso, resulta sumamente llamativo que los dos trabajos más emblemáticos de estas dos tendencias desarrolladas dentro de la historia social compartan tan alto grado de ideologización: el formato de ensayo de Ciudadanos imaginarios y de La tradición republicana del buen gobierno, y su visión totalizante sin matices se encuadra en una interpretación del siglo XIX con fines partidistas, en la que se obvia la contingencia y, con ella, las complejidades y las contradicciones. Sus planteamientos recuerdan sobremanera a los debates mantenidos por los padres de la patria en el siglo XIX: reproducen determinadas interpretaciones históricas con fines marcadamente políticos. Para unos y para otros el momento precedente (en aquel momento la colonia, en éste el siglo XIX) justifica una incapacidad o disposición, respectivamente, intrínseca a lo que se define como el ser mexicano, con el fin último de criticar a los que detentan el poder político en el presente (los españoles en el XIX, el PRI en su momento) o, en el segundo caso, para respaldarlos. Todo ello en un momento de cambio y, por lo tanto, de necesidad de redefinición política (el paso del orden colonial a la independencia mexicana, el paso del dominio del PRI por 80 años a lo que se ha dado en llamar la "transición a la democracia"). La reproducción alcanza los tópicos acerca

${ }^{49}$ Hammett, "Formación", 1993, pp. 103-120. de la visión de la propia historia nacional: mientras Escalante culpa a la tradición de la colonia, Alicia Hernández recupera muy positivamente dicha tradición.

NuEVAS PROPUESTAS DESDE LA HISTORIA POLÍTICA Y CULTURAL

El recorrido hasta aquí realizado por las diferentes propuestas que han tratado de aportar una visión más comprehensiva del liberalismo mexicano en el siglo XIX básicamente ha delineado dos ámbitos: el que continúa y actualiza el debate de los propios liberales del XIX y el que, concebido al hilo de la transformación de la historia social, se bifurca en la respuesta sobre el éxito o fracaso en el proceso de construcción del Estado liberal. Sin embargo, tal y como se mencionó anteriormente, la crisis de los principales paradigmas que habían constituido verdades indiscutibles que cimentaban las ciencias sociales ha ocasionado una eclosión epistemológica generadora tanto de una multiplicidad de nuevos temas, enfoques y metodologías, como de una recuperación de perspectivas de análisis que habían permanecido poco transitadas ante el monopolio de la historia social. Así es como se explica el recobrado interés por el estudio de la política y la inusitada atención a lo cultural en los estudios históricos; los más rupturistas, además, transitan la frontera entre una y otro con el fin de replantear nuevos interrogantes a temáticas cuyo estudio se creía más que saturado. En este sentido, las contribuciones más relevantes atienden al análisis de los procesos simbólicos en relación con las prácticas sociales, y centran su interés en cuestiones como la resemantización de algunos con- 
ceptos clave para la nueva definición política (libertad, ciudadanía, representación, soberanía, legitimidad) o en el análisis de la gestación y difusión de los imaginarios nacionales, entre otros.

Los principales trabajos que han roto la dinámica de reproducción de ciertos tópicos y han generado un nuevo debate han sido prácticamente los relativos a las elecciones o a los procesos electorales. Si durante un tiempo estos temas no habían suscitado mucho interés al considerar que un sufragio censatario y unas elecciones corruptas eran poco significativos, ${ }^{50}$ ahora se ha hecho especial hincapié no sólo en su carácter incluyente, sino en lo que supuso en el proceso de construcción y aprehensión de un imaginario político nuevo. Esta búsqueda de una nueva propuesta interpretativa para el paso del mundo colonial al liberal puede datarse a fines de los ochenta, con el trabajo coordinado por Antonio Annino, America Latina: dallo Stato coloniale allo Stato nazione ${ }^{51}$ que, junto con De los imperios a las naciones: Iberoamérica, ${ }^{52}$ constituye el ensayo seminal de una visión que en la actualidad se encuentra en su momento de mayor creatividad. De factura desigual, en ambos volúmenes puede encontrarse aún la fuerza de la tercera corriente de interpretación y el destello de un camino que se atisba sumamente fértil. Un buen ejemplo lo constituye el trabajo del propio Annino quien, habiendo sido uno de los exponentes de la tercera tendencia historiográfica que aquí se ha caracterizado, ha sido a su vez y con el paso del tiempo uno de los

so Así lo hizo notar Bushnell en "Evolución", 1987, pp. 615-632.

si Annino, Carmagnani et al., America, 1987.

52 Annino, Castro Leiva y Guerra, Imperios, 1994. precursores de la cuarta. Tomando como objeto de análisis las elecciones de 1812 en la ciudad de México con el fin de estudiar la relación existente entre los antiguos poderes y sus formas de legitimación, por un lado, y los nuevos y las suyas, por otro, concluye que el problema de la gobernabilidad en México se debió no a la debilidad, sino a la fuerza de la ciudadanía moderna. Argumenta que la difusión de la ciudadanía liberal fue anterior a la obtención de la independencia y que su redefinición en clave localista, como consecuencia de la necesidad que tenían las elites del apoyo de los municipios, convirtió a las comunidades locales en fuentes de derechos políticos frente a una consideración abstracta y homogénea de los mismos. El resultado de este proceso fue que el municipio se constituyó en un poder que limitaba la capacidad de injerencia del Estado en las sociedades locales. En este sentido, según Annino, el gran reto de la elite del siglo XIX mexicano no fue la divulgación de los valores de la ciudadanía en una sociedad que la rechazaba por ser tradicional, sino el de poder controlarla como práctica social. De hecho, concluye, fue en la pervivencia de las libertades territoriales y corporativas en donde se produjo el primer choque entre el liberalismo y la tradición criolla. ${ }^{53}$ Influido por el "giro lingüístico" experimentado en las ciencias sociales en la dé-

${ }^{53}$ A diferencia de los autores anteriores, que defendían la existencia de un liberalismo popular surgido básicamente durante las guerras de mitad de siglo XIX, Annino comparte con los autores que siguen en este texto la idea de que fue durante los años del constitucionalismo gaditano cuando se da el paso hacia dicho liberalismo popular. Annino, "Ciudadanía", 1999, pp. 62-93. 
cada de los ochenta, ha dedicado una parte importante de su trabajo al análisis de la diferencia valorativa y de uso que cada grupo social daba a conceptos clave en un momento determinado: aunque la elite y el pueblo compartían nociones como la de soberanía o la de libertad, la primera lo hacía en términos modernos, y el segundo, en los tradicionales. ${ }^{54}$

Estos análisis de los procesos electorales, puede decirse de forma casi genérica, han convulsionado la naturaleza de los estudios sobre el siglo XIX mexicano y han creado un campo en el que la historia de las ideas en su vertiente cultural, y más concretamente, la que atiende a la construcción de imaginarios y modelos comprehensivos del mundo ha dado los frutos más jugosos. Entre ellos destacan los de François Xavier Guerra, Jaime E. Rodríguez y el mismo Antonio Annino. ${ }^{55} \mathrm{Su}$

${ }^{54}$ Habla de la diferencia entre el idioma y los valores en Annino, "Jano", 1993, p. 180.

${ }^{55} \mathrm{Me}$ he limitado a mencionar a estos autores únicamente por economía de espacio. Los he seleccionado entre otros porque he considerado que ellos fueron, en cierta medida, los iniciadores de este revisionismo, cuentan con líneas de investigación en este sentido muy consolidadas que son secundadas por otros historiadores y porque han sido los que mayor difusión han tenido en el ámbiro académico. Sin duda habría que introducir otros estudios, como el de Vázquez, "Liberales", 1997, pp. 1.53-175. Se trata de un artículo clarificador en el que hace un recorrido en la formación y definición del pensamiento liberal y el conservador en México desde la independencia hasta la guerra de Reforma, hecho con el fin de superar ciertos estereotipos historiográficos tan consolidados por lo que denomina "historia oficial". Entiendo que salvo esta peculiaridad concreta, el artículo se inscribe en la caracterización general que hago de este tipo de estudios. Lo mismo ocurre con otros trabajos, como por ejemplo los de Virginia Guedea. gran aportación se debe a su concepción de la modernidad desde una perspectiva mucho más amplia y abarcadora que la estrictamente social o económica definidas por los modelos anteriores; le interesa la interpretación del cambio como una transformación global que afecta a todas las esferas, desde el modo en que el hombre se concibe a sí mismo hasta la manera como se constituye y concibe la comunidad política. Este enfoque ha socavado ciertos tópicos tradicionalmente aceptados y por ello ha evidenciado la necesidad de trabajar temáticas habituales desde nuevas perspectivas, así como la de abrir otras nuevas. En general la mayor parte de ellos se han dedicado al análisis del proceso independentista, cuestionando las interpretaciones más convencionales; todos comparten las valoraciones siguientes. ${ }^{56}$

Por un lado, analizan el proceso de introducción de los principios liberales conectándolo con el periodo de la colonia, en una visión temporal de mayor amplitud que en la interpretación historiográfica anterior. No respetan el tradicional tópico que fija el inicio de la ruptura y la gestación de lo nuevo en el momento independentista, sino que consideran que hay una etapa en la que se empiezan a generar las nuevas ideas ilustradas (fines del XVIII) sobre las que se asentará la nueva definición política surgida ante la crisis de la monarquía hispánica. Por ello se replantean la datación de las diferentes etapas del desarrollo histórico mexicano: el

"56 En el caso de Guerra resulta significativo que su estudio más conocido fuera el de México, 1988, cuando en realidad, sus propuestas más interesantes quedan recogidas en Modernidad, 1992, así como en diversos artículos posteriores de tema independentista. Ello quizá se deba a la difusión editorial. 
cambio del mundo colonial al moderno ya no se fija en una fecha sino en un periodo de mayor amplitud y que abarcaría desde fines del XVIII a mediados del XIX. En cualquier caso, si se quiere destacar algún año como el del inicio de la transformación, ya no serán ni 1810 ni 1821 , años vinculados con la obtención de la independencia, sino más bien 1808 , momento de crisis de la monarquía hispánica, o 1812, relacionado con la aprobación de la Constitución de Cádiz, cuyas disposiciones serán fundamentales para comprender el posterior desarrollo político del país. ${ }^{57} \mathrm{~A}$ partir de entonces, en el ámbito de las prácticas sociales, mentales y políticas, conviven lo antiguo con lo nuevo sin generar necesariamente contradicciones. Así, con este nuevo punto de partida, observando desde el "antes" y no desde el "deber ser", el proceso se puede observar en toda su complejidad desde el punto de vista de la progresiva y contingente transformación (que no malformación) de lo viejo en lo nuevo dentro de un modelo propio y no definido como "importado". Su visión es, en definitiva, propiamente histórica.

En este mismo sentido, reivindican la existencia de una tradición española liberal que se fragua durante las Cortes de Cádiz y que entronca, aunque con torsiones importantes, con el sistema de representación existente durante la fase final de la colonia. Reconocen el protagonismo de la asamblea gaditana en la definición de

\footnotetext{
57 Tal es el caso de Guerra y de Rodríguez; también el propio Annino reconoce que lo ocurrido durante la crisis dinástica fue fundamental para comprender la lucha posterior de los pueblos por defender sus derechos.
}

la modernidad política del área hispana, ${ }^{58}$ al considerar, por ejemplo, que fue entonces cuando se gestó y difundió el nuevo concepto de soberanía del que se apropiaron los municipios para argumentar en defensa de sus territorios, una muestra más del proceso de incorporación del lenguaje nuevo con valores antiguos. Así es como explican que el Estado mexicano del XIX se formara sobre una base municipalista, resultado de la crisis de la tradición española ${ }^{59}$ por lo que adquirió un carácter específico frente a otros casos históricos; con esta interpretación, el problema de la "inadecuación de la realidad hispana al modelo", entendido siempre como modelo ideal supuestamente materializado en la tradición inglesa o francesa, queda fuera de lugar. ${ }^{60}$ El debate sobre el éxito o el fracaso del establecimiento de un Estado liberal, en cualquier caso, ya no resulta relevante.

Bajo estos presupuestos, en el caso concreto de la explicación del proceso emancipador y en contra de las tesis tradicionalmente aceptadas, estos trabajos demuestran que el deseo inicial de las elites novohispanas no fue la obtención de la independencia, sino que más bien ésta

${ }^{58}$ Ésta es la propuesta mejor elaborada por Guerra.

59 Tesis defendida principalmente por Annino, en su introducción a Historia, 1995.

${ }^{60}$ Annino explica cómo la consideración del liberalismo como un fracaso fue en gran medida formulada por algunos hombres del xIX porque ellos, siguiendo el modelo de Constant, consideraron incompatible la coexistencia, por ejemplo, de las dos ideas de libertad, mientras que la realidad demostró que a pesar de tener un concepto antiguo de libertad, los pueblos accedieron al universo liberal. In Annino, "Jano", 1993, p. 181. 
derivó de dos acontecimientos inseparables: la revolución acaecida en la península ibérica y el proceso de disolución general de la monarquía hispana, en palabras de Jaime E. Rodríguez, o el de modernización, según Guerra.

Por último, ponen de relieve que la configuración de los diferentes Estados en América Latina fue el resultado de la redefinición política surgida al hilo de los acontecimientos de los procesos independentistas. Con ello echan por tierra los tópicos simplistas y recurrentes en las interpretaciones nacionalistas de la historia que sostenían la preexistencia de las naciones al Estado y explicaban la victoria independentista como el éxito de las demandas de éstas. En definitiva, estos análisis demuestran cómo cada nuevo Estado nacido tras la emancipación de España forjó la idea de la existencia de una identidad propia y diferenciada como una estrategia efectiva para obtener la lealtad y fomentar la cohesión de la ciudadanía.

Siendo éste el marco general que todos los historiadores antes mencionados comparten, cada uno de ellos ha tratado problemáticas más específicas. Así, François Xavier Guerra ha realizado numerosas propuestas referidas a la modernización del imaginario político del siglo XIX. Mediante su aplicación del modelo habermasiano, y en concreto del análisis de là formación de la esfera pública (los espacios públicos de discusión y crítica), redefine el papel de "los intermediarios" de una manera mucho más compleja, rica y sobre todo menos maniquea que la propuesta por Escalante. Los modos modernos de sociabilidad generaron un cambio en la manera en que el individuo se percibía a sí mismo y al conjunto de la sociedad. Dicha revolución supuso principalmente un cambio profundo en la concepción del hombre (individual y sin los vínculos de la antigua sociedad corporativa y estamental), de la sociedad (contractual, surgida de un nuevo pacto social) y de la política (expresión de un nuevo soberano, el pueblo); en definitiva, un nuevo sistema global de referencias en que se combinan las ideas, imaginarios sociales, valores y comportamientos que debían configurar al nuevo hombre y a la nueva sociedad, cambios ocurridos, y he aquí la novedad de los mismos, en la escena pública. ${ }^{61}$ Por tanto, Guerra considera que la piedra angular de la dinámica social no se encuentra en la asunción por parte de la elite de la idea de oposición entre ella y el resto de la sociedad, sino en la existencia de una gran distancia entre la modernidad legal y el tradicionalismo de los imaginarios y comportamientos de la mayor parte de la sociedad, incluida la propia elite. ${ }^{62}$

Por su parte, Jaime E. Rodríguez ha seguido el desarrollo de las propuestas autonomistas en Nueva España y ha demostrado cómo éstas finalmente llevaron a posturas independentistas ante la ausencia de respuesta a sus demandas por parte de los peninsulares. ${ }^{63}$ Con ello defiende la tesis de que la independencia americana no fue el resultado de un movimiento anticolonial, cuya última fase se identificaba con los alcances de la Constitución de Cádiz, sino que incluso se con-

ol Guerra, Modernidad, 1992, y Guerra, Lempérière et al., Espacios, 1998.

${ }_{62}$ Guerra, "Independencia", 1993, pp. 1.5-48.

${ }_{63}^{63}$ Las hipótesis de Rodríguez en gran medida se sustentan en los trabajos realizados por Virginia Guedea acerca del comportamiento de la elire nacional desde 1808 hasta 1821 , tal y como él mismo reconoce en Rodríguez, "Transición", 1993, p. 266. 
tinuó aplicando sus principios, perviviendo su particular sistema representativo $y$, a la vez, y mediante la creación de ayuntamientos, incorporando al proceso político a sectores sociales hasta entonces excluidos. Lo que, por otro lado, la victoria independentista sí produjo fue una fractura en el espacio social, económico y político compartido por todo el ámbito de la monarquía hispana, hasta entonces lo suficientemente flexible como para resolver cualquier tipo de tensión; este resquebrajamiento y la coyuntura internacional en la que se desarrolló constituyen las causas, según Rodríguez, de la gran inestabilidad política y la ausencia de crecimiento económico de la América hispana, por lo menos hasta $1870 \mathrm{y}$, sobre todo, en comparación con la América sajona. Sin embargo, y a pesar de las independencias, todos los países herederos de la desintegración de la monarquía desarrollaron una política similar en la medida en que todos ellos compartían una misma cultura política basada en sus propias tradiciones y experiencias, y no en un modelo importado. ${ }^{64}$

Los últimos años han dado lugar a importantes transformaciones conceptuales y metodológicas en el mundo de las ciencias sociales, que han convulsionado tanto las perspectivas de análisis como las temáticas abordadas. Por un lado, la supetación de la dialéctica del materialismo y el auge de la interdisciplinariedad han generado un utillaje mucho más dúctil que permite relecturas completamente distintas de problemas ya conocidos. Por otro, los nuevos paradigmas han permitido iden-

\footnotetext{
${ }^{64}$ Rodríguez, Independence, 1998, p. 246.
}

tificar problemáticas que hasta fechas recientes apenas suscitaban el interés académico. El estado actual de la historiografía apuesta por aquellas miradas más históricas y menos prejuiciadas del devenir histórico, que permitan presentar, además, las complejidades y contradicciones de la realidad que se somete a análisis.

En el caso concreto del estudio del liberalismo mexicano decimonónico, los trabajos más recientes ya no parten de modelos teóricos ideales para comprender las dinámicas de transformación del orden colonial en el liberal, sino que lo hacen desde la propia información recibida por las fuentes. Aún queda, sin embargo, para la mayoría de ellos, la labor de superar la visión forjada únicamente desde los conceptos de oposición y exclusión y destacar los elementos comunes y los puntos de conexión e intercambio entre los diferentes actores sociales.

En este contexto epistemológico aparecen temáticas que no han sido exploradas en profundidad por la historiografía tradicional, bien por haberlas desestimado por antirrevolucionarias (los conservadores o la Iglesia) o bien, simplemente, por olvido (la milicia nacional). Por otro lado, la aceptación de la coexistencia, resemantización y sustitución de elementos constitutivos del orden antiguorregimental por los modernos, hace necesarias nuevas lecturas de procesos como las elecciones, las rebeliones campesinas o los estallidos de violencia, entre otros, que superen las explicaciones unidireccionales aportadas por la historia oficial, reorientando la comprensión de estas dinámicas sociales como procesos de reconocimiento, modificación y asimilación de las nuevas prácticas liberales. Por último, el carácter pro- 
cesal, dinámico y contingente del proceso de consolidación del Estado liberal pone de relieve la necesidad de estudiar con mayor profundidad la participación de la periferia en los avatares de la definición y conformación del mismo.

La construcción historiográfica se hace tanto por acumulación como por discusión con las ideas contrarias. Gracias a su permanente renovación el pasado siempre aparece como un país extraño; la aventura consiste en crear nuevos caminos que nos permitan acercarnos a él.

\section{BiBLIOGRAFÍA}

-Annino, Antonio (coord.), Historia de las elecciones en Iberoamérica, siglo XIX: la formación del espacio político nacional, FCE, Buenos Aires, 1995.

—_ "Nuevas perspectivas para una vieja pregunta" en Antonio Annino y Raymond Buve (coords.), El liberalismo mexicano, pp. 5-13. "El jano bifronte: una aproximación tentativa" en Antonio Annino y Raymond Buve (coords.), El likeralismo mexicano, pp. 179-186. —, "Ciudadanía 'versus' gobernabilidad republicana en México. Los orígenes de un dilema" en Hilda Sabato (coord.), Ciudadanía politita y formación de las naciones. Perspectivas históricas de América Latína, pp. 62-93.

-Annino, Antonio y Raymond Buve (coords.), El liberalismo mexicano, AHILA, Hamburgo-Münster, 1993.

-Annino, Antonio, Marcelo Carmagnani et al. (coords.), America Latina: dallo Stato coloniale allo Stato nazione. América Latina: del Estado colonial al Estado nación, Franco Angeli, Milán, 1987.

-Annino, Antonio, Luis Castro Leiva y François-Xavier Guerra, De los imperios a las naciones: Iberoamérica, Ibercaja, Zaragoza, 1994.
-Bonfil Batalla, Guillermo, México profundo. Una civilización negada, Grijalbo, México, 1994 (1987).

-Bellingeri, Marco, "Soberanía o representación: legitimidad de los cabildos y la formación de las instituciones liberales" en Montalvo Ortega (coord.), El Águila Bifronte. Poder y liberalismo en México, pp. 65-91.

, "Del voto a las bayonetas: experiencias electorales en el Yucatán constitucional e independiente" en Enrique Montalvo Ortega (coord.), El águila bifronte. Poder y liberalismo en México, pp. 91-ג19.

-Bobbio, Norberto, Liberalismo y demurracia, FCE, México, 1992 (1966).

-Brading, David, "Liberal Patriotism and the Mexican Reforma", Journal of Latin American Studier, núm. 10, 1979, Cambridge, pp. 27-45.

-Burns, E. Bradford, La pobreza del progreso, Siglo XXI, México, 1990.

-Bury, John, La idea del progreso, Alianza, Madrid, 1971.

-Bushnell, David, "La evolución del principio representativo, de liberal a democrático, en Latinoamérica independiente" en Antonio Annino, Marcelo Carmagnani et al. (coords.), America Latina: dalla Stato coloniale allo Stato natione, vol. II, pp. 615-632.

-Buve, Raymond, "Transformación y pattonazgo político en el siglo Xxı, México rural: continuidad y cambio entre 1867 y 1920" en Antonio Annino y Raymond Buve (coords.), El liberalismo mexicano, pp. 143-176.

-Carmagnani, Marcelo, "Finanzas y Estado en México, 1820-1880" en Enrique Montalvo Ortega (coord.), El águila bifronte. Poder y liberalismo en México.

—_ - "La libertad, el poder y el Estado antes de la revolución" en Enrique Montalvo Ortega, El águila bifronte. Poder y liberalismo en México, pp. 223-242.

-Carmagnani, Marcelo y Alicia Hernátdez Chávez, "La ciudadanía orgánica mexicana, 
1850-1910" en Hilda Sabato (coord.), Cizdadanía politica y formación de las naciones. Perspectivas bistóricas de América Latina, pp. 371-405.

-Carrasco Altamirano, Diódoro (presentación), Ideario del liberalismo, Secretaría de Gobernación, México, 2000.

-Cerutti, Mario, "Siglo XIX. Revista de Historia", Historia Mexicana, vol. I, núm. 4, abriljunio, 2001, México, pp. 899-920.

- Cien años de Daniel Cosío Villegas, Clío/El Colegio Nacional, México, 1999.

-Colom, Francisco, Razones de identidad, Anthropos, Barcelona, 1998.

-Connaughton, Brian, Dimensiones de la identidad patriótica. Religión, política y regiones en México. Siglo XIX, UAM/Miguel Ángel Porrúa, México, 2001.

-Constant, Benjamin, Sobre la libertad de los antiguos y de los modernos, Tecnos, Madrid, 2002.

- Cosío Villegas, Daniel, Historia moderna de México, Hermes, México, 1955.

-Escalante Gonzalbo, Fernando, Ciudadanos imaginarios. Memorial de los afanes y desventuras de la virtud y apología del vicio triunfante en la república mexicana. Tratado de moral pública, Colmex, México, 1999 (1992).

-Ferrer Muñoz, Manuel y María Bono López, Pueblos indigenas y Estado nacional en México en el siglo XIX, UNAM, México, 1998.

-Florescano, Enrique, "La interpretación del siglo XIX" en Alicia Hernández Chávez y Manuel Miño Grijalba (coords.), Cincuenta años de bistoria en México en el cincuentenario del Centro de Estudios Históricos, Colmex, México, 1993, vol. I, pp. 29-56.

-González y González, Luis, El indio en la era liberal, Clío/El Colegio Nacional, México, 1996.

-González Navarro, Moisés, “Tipología del liberalismo mexicano", Historia Mexicana, vol. XxxiI, núm. 2, 1982, México, pp. 198-225.

-Gray, John, Liberalismo, Alianza, Madrid, 1992 (1986).
-Guerra, François-Xavier, México: del antiguo régimen a la revolución, FCE, México, 1988 (1985). - Modernidad e independencias, Colecciones Mapfre, Madrid, 1992.

"La desintegración de la monarquía hispánica: revolución e independencias" en Antonio Annino, Luis Castro Leiva y François Xavier Guerra, De los imperios a las naciones: Iberoamérica, pp. 195-227.

"El soberano y su reino. Reflexiones sobre la génesis del ciudadano en América Latina" en Hilda Sabato (coord.), Ciudadanía política y formación de las naciones. Perspectivas bistóricas de América Latina, pp. 33-61.

"La independencia de México y las revoluciones hispánicas" en Antonio Annino y Raymond Buve, El liberalismo mexicano, .p., 15-48. , Annick Lempérière et al., Los espacios públicos en Iberoamérica. Ambigüedades y problemas. Siglos XVIII-XIX, FCE/CEMCA, México, 1998.

-Hale, Charles, El liberalismo mexicano en la época de Mora, Siglo XXI, México, 1999.

, The Transformation of Liberalism in Late Nineteenth-century Mexico, Princeton University Press, Princeton, 1989.

— "Los mitos políticos de la nación mexicana: el liberalismo y la revolución", Historia Mexicana, vol. XLVI, núm. 184, abril-junio, 1997, pp. 821-837.

-Hamnett, Brian R., "La formación del Estado mexicano en la primera época liberal, 18121867" en Antonio Annino y Raymond Buve (coords.), El liberalismo mexicano, pp. 103-120.

-Hernández Chávez, Alicia, La tradición republicana del buen gobierno, FCE/COLMIX, México, 1993.

-Irurozqui, Marta, A bala, piedra y palo. La construcción de la ciudadanía política en Bolivia, 1826-1952, Diputación de Sevilla, Sevilla, 2000.

-Knight, Alan, "El liberalismo mexicano desde la reforma hasta la revolución (una interpretación)", Historia Mexicana, núm. 35, 1985, México, pp. 59-91. 
-Lyotard, Jean François, La condición postmoderna: informe sobre el saber, Cátedra, Madrid, 1987.

-Litvak, Lily, Latinos y anglosajones: origenes de una polémica, Puvill-Editor, Barcelona, 1980.

-Mallon, Florencia E., Peasant and Nation: the Making of Postcolonial Mexico and Peru, University of California Press, Berkeley, 1995.

-Montalvo Ortega, Enrique (coord.), El águila bifronte. Poder y liberalismo en México, INAH/CNCA, México, 1995.

-Morales, Humberto y William Fowler (coords.), El conservadurismo mexicano en el siglo XIX (1810-1910), Benemérita Universidad Autónoma de Puebla/University of Saint Andrews/Secretaría de Cultura/Gobierno del Estado de Puebla, México, 1999.

-Morse, Richard, El espejo de Próspero. Un estudio de la dialéctica del Nuevo Mundo, Siglo XXI, México, 1982.

-Noriega, Alfonso, Pensamiento conservador y conservadurismo mexicano, IJJ-UNAM, México, 1972.

-Pietschmann, Hörts, "La historia de América Latina como subdisciplina histórica", Diá$\log _{0}$ Científico, Centro de Comunicación Científica con Iberoamérica, vol. 9, núms. 1-2, 2000, Tubinga, pp. 9-45.

-Quijada, Mónica, “QQué nación? Dinámicas y dicotomías de la nación en el imaginario hispanoamericano del siglo XIX" en François Xavier Guerra y Mónica Quijada (coords.), Imaginar la nación, AHILA, Münster-Hamburgo, 1994, pp. 15-51 (Cuadernos de Historia Latinoamericana, núm. 2).

-Quijada Mónica, Carmen Bernand y Arnd Schneider, Homogeneidad y nación. Con un estudio de caso: Argentina, siglos XIX y XX, Consejo Superior de Investigaciones Científicas, Madrid, 2000.

-Reyes Heroles, Jesús, "Las libertades en el liberal ismo mexicano", Cuadernos Americanos, año XV, vol. LXXXVIII, 1956, México, pp. 179-201.
- El liberalismo mexicano, I. Los orígenes, 11. La sociedad fluctuante. $11 \mathrm{l}$. La integración de las ideas, FCE, México, 1974 (1961).

- Ideario del liberalismo, Secretaría de Gobernación, México, 2000.

-Rodríguez, Jaime, The Independence of Spanish America, Cambridge University Press, Cambridge, 1998.

- "La Constitución de 1824 y la formación del Estado mexicano", Historia Mexicana, vol. xu, núm. 3, 1991, México, pp. 507-535. , "La transición de colonia a nación: Nueva España, 1820-1821", Historia Mexicana, vol. XIIII, núm. 2, 1993, México, pp. 265-322.

-Sabato, Hilda (coord.), Ciudadanía política y formación de las naciones. Perspectivas históricas de América Latina, FCE/COLMEX, México, 1999 (1997).

-Staples, Anne et al., El dominio de las minorias. República restaurada y porfiriato, COl.MEX, México, 1989.

-Thomson, Guy P. C., "Popular Aspects of Liberalism in Mexico", Bulletin of Latin American Research, vol. 10, núm. 3, 1991, Oxford, pp. 265-292.

"La 'Bocasierra': ¿cuna del liberalismo? Tres municipios serranos entre $1.855 \mathrm{y}$ 1889" en Antonio Annino y Raymond Buve (coords.), El liberalismo mexicano, pp. 121-141.

, "Movilización conservadora, insurrección liberal y rebeliones indígenas, 1854 76" en Antonio Annino, Marcelo Carmagnani et al. (coords.), America Latina: dallo Stato coloniale allo Stato nazione, vol. II, pp. 592-61.5.

-Urías Horcasitas, Beatriz, Historia de una negación: la idea de igualdad en el pensamiento político mexicano del siglo XIX, Instituto de Investigaciones Sociales-UNAM, 1996.

-Vázquez, Josefina Zoraida, "Liberales y conservadores en México: diferencias y similitudes", Cuadernos Americanos, año XI, vol. 6, núm. 66, 1997, México, pp. 153-175. 


\section{SECUENCIG}

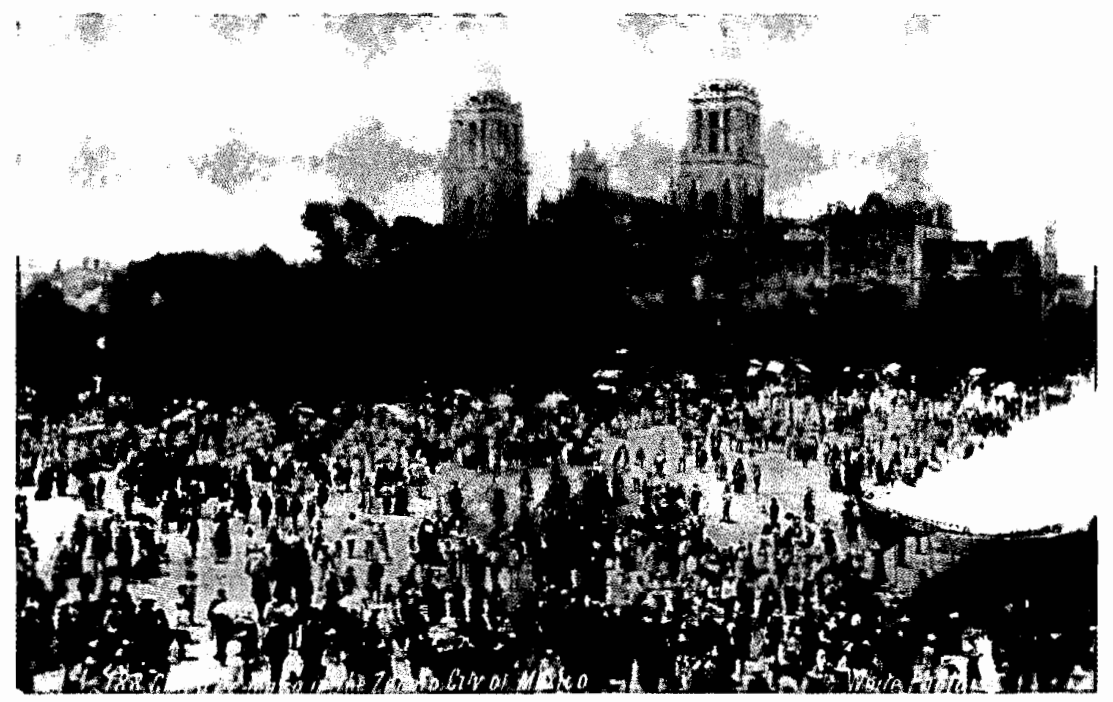

